\title{
Time Allocation to the Reproductive and Feeding Behaviors in the Male Cabbage Butterfly
}

\author{
Tadao Hirota* and Yoshiaki Obara \\ Laboratory of Ethology, Department of Veterinary Medicine, Tokyo University of Agriculture and Technology
}

\begin{abstract}
Individually marked males of Pieris rapae crucivora, were observed to determine how they allocate time to reproduction and feeding. Males were found to alternately feed and search for females. This manner of time allocation persisted throughout the day. The total times that males allocated to the two behaviors were positively correlated, i.e. those males that spent longer searching for females, also feed for longer periods. Males, however, tended to allocate more time to the female-searching in the morning than in the afternoon, while time allocated to feeding throughout the day. Older males spent more time searching for females in the morning. The body weight of male butterflies also changed as they aged. The results are discussed in terms of both proximal and ultimate aspects of female-search.
\end{abstract}

\section{INTRODUCTION}

It is established that most male reproductive effort is devoted to mate finding. Especially in those species lacking parental care, a male's reproductive success is largely determined by the number of matings. This causes competition among males for the access to females. The competition is more intense when the operational sex ratio is male-biased (Emlen and Oring, 1978; Owens and Thompson, 1994; Kvarnemo and Ahnesjö, 1996). Such intense competition is believed to produce different mate finding strategies, including territorial behavior, attraction of females by signaling, active search and so on. Thornhill and Alcock (1983) argued that scramble competition occurs when male territoriality is less advantageous, either when many males compete intensely for scare females, or when it is difficult to predict the availability of females. In such cases males can afford little for female guarding, the most important factor affecting mate securing may be the ability to locate mates as quickly and steadily as possible (Odendaal et al., 1985).

Scramble competition is predicted to produce an ideal free distribution in which the competitors distribute in relation to the abundance of resource so that each individual enjoys the same availability of the resource (Fretwell, 1972). To verify this hypothesis, it is important to know when and for how long each male searches for mates. In lepidopterans there have been few observations of individuals' behaviors throughout entire days. This is because it is difficult in the field to track specific individuals all day long, and it is impossible to prevent the males from dispersing.

Scramble competition occurs in the cabbage butterfly, $P$.

\footnotetext{
* Corresponding author: Tel. +81-042-367-5623; FAX. +81-042-367-5623 E-mail.columbo@cc.tuat.ac.jp
}

rapae crucivora (Suzuki, 1980; Ohsaki, 1982). In this species the male actively flies in search for females and immediately on finding virgin females he attempts to mate them (Ohtani, 1985). Male search for females occurs more frequently in the morning. Iwasa and Obara (1989) suggested, on the basis of a mathematical model that temporal change of the number of searching males in a day should parallel the likelihood of finding virgin females, most of which emerge in the early morning. In order to determine how males allocate time to femalesearching and to feeding, observation of the behaviors of individual males were made from dawn to dusk in a large pseudonatural cage. In addition, the age-dependent change in males' body weight was investigated, since the preliminary observation suggested that the older males were lighter and that this may affect the female-search by males.

\section{METHODS}

Insects

Butterflies were collected in Fuchu-City, Tokyo, Japan. They were allowed to lay eggs on the leaves of potted cabbages, Brassica oleracea L., in meshed cages $(30 \times 30 \times 45 \mathrm{~cm})$. Cages were kept in a mesh-walled tent in the field and eggs were allowed to develop into pupae in a natural condition. The adult males were anaesthetized with $\mathrm{CO}_{2}$ gas on the day of emergence to mark them with oil-soluble markers of different colors on the dorsal surface of their wings. The marked males were put in an outdoor cage $(12 \times 24 \times 2 \mathrm{~m})$ on a field in the campus of Tokyo University of Agriculture and Technology. Cabbages were planted in a cultivated field of $10 \times 20 \mathrm{~m}$ inside the cage. Buckwheat (Fagopyrum esculentum) was planted in a corner $(2 \times 10$ $\mathrm{m}$ ) of the field and its flowers served as the nectar source for the butterflies. Thirty seven male butterflies were allowed to fly freely within the cage.

\section{Observation}

Observations were carried out in July and August in 1996. Every five minutes from 6:00 to 17:00, we scanned the cabbage field and buckwheat site for males engaged in searching for female or sipping 
nectars from buckwheat flowers, respectively, and recorded which males were engaged in either behavior. The total time invested in female-search or feeding was estimated by multiplying the number of times each male was observed to perform either behavior by five minutes. The female-search behavior of the male was characterized by slow zigzag flight and close to the leaves of $B$. oleracea (Obara, 1964; Ohtani, 1985). Males were also frequently observed flying under the leaves of $B$. oleracea for female-search. In the present study, no females were released in the cage so that males could not encounter females and mate. This enabled us to exclude the effect of copulation career on female-search behavior (Rutowski, 1979). Two successive landings on different flowers were regarded as a visitation to flowers for nectar. This criterion was adopted to discriminate visitation for feeding from random landings on flowers for other purposes. We could distinguish searching behavior from feeding behavior, since the host plants, $B$. oleracea were planted away from the nectar plants, $F$. esculentum.

Preliminary observation suggested that male body weight changed with age. To assess weight changes through adult life, 15 males were released into the cage on the day of emergence, and allowed unrestricted behaviors. At 16:00 every day subsequent to release, they were caught, anaesthetized with $\mathrm{CO}_{2}$ gas, weighed and released back into the cage.

\section{RESULTS}

The observations revealed that the males' daily activities followed a routine schedule (Fig. 1). They took off early in the morning from the bush where they had roosted overnight and flew to the cabbage field, where they began searching for females. Behavior was not, however, exclusively femalesearching. Frequently they left the cabbage field to visit and feed from the nectar flower, thereafter returning to the cabbage field to resume female-search. They alternated femalesearch and feeding through the rest of morning. During the afternoon they became less active with the time, finally leaving the cabbage field late in the afternoon to move to bush on the edge of cabbage field to roost. This daily schedule is basi- cally similar to that for wild males in an open field (Obara, unpublished).

This is contrasted to the temporal change of investment in the feeding activities, which did not change so markedly throughout the day time, although there is a shallow peak between 9:30 and 11:30. The proportion of active males indulging in female-searching behavior declined through the day, being inversely correlated with time of day (Fig. 2; Kendall's correlation test, $\tau=-0.40, n=74$ observations, $\mathrm{p}<0.001)$.

Estimated total time of female-search or feeding varied markedly between males, and it was found that those males who spent longer searching for females also fed more often and for a longer total time (Fig. 3; Kendall's correlation test, $\tau=0.50, n=35, p<0.001)$.

To reveal a possible effect of a male's age on his time allocation, we compared the time allocation of males whose daily behavior was successfully followed all day long on three successive days of unchanged weather. The median time of female-searching behavior did not change with males' age (Fig. 4A; $T c=0.11, k=18$ males, $n=3$ days, $p=0.56$, refer to Siegel and Castellan, 1988), while that of feeding behaviors seemed to be delayed as they aged, although the correlation between them was significant (Fig. $4 B$; $T c=0.31, k=18, n=3$, $p=0.045)$. To determine whether they allocated time to female-search and feeding behavior at different times of day, we subtracted the median time of the female-searching from that of feeding for each male. Figure $4 \mathrm{C}$ shows that male allocated time to feeding later in a day as they aged $(\mathrm{Tc}=0.37$, $k=18, n=3, p=0.019$ ).

On the other hand, the termination times of female-search and feeding behavior were not significantly correlated with males' adult age $(\mathrm{k}=18, \mathrm{n}=3, \mathrm{Tc}=0.00, \mathrm{p}=1.00 ; \mathrm{Tc}=0.09$, $p=0.61$, respectively). The ratio of total time of feeding

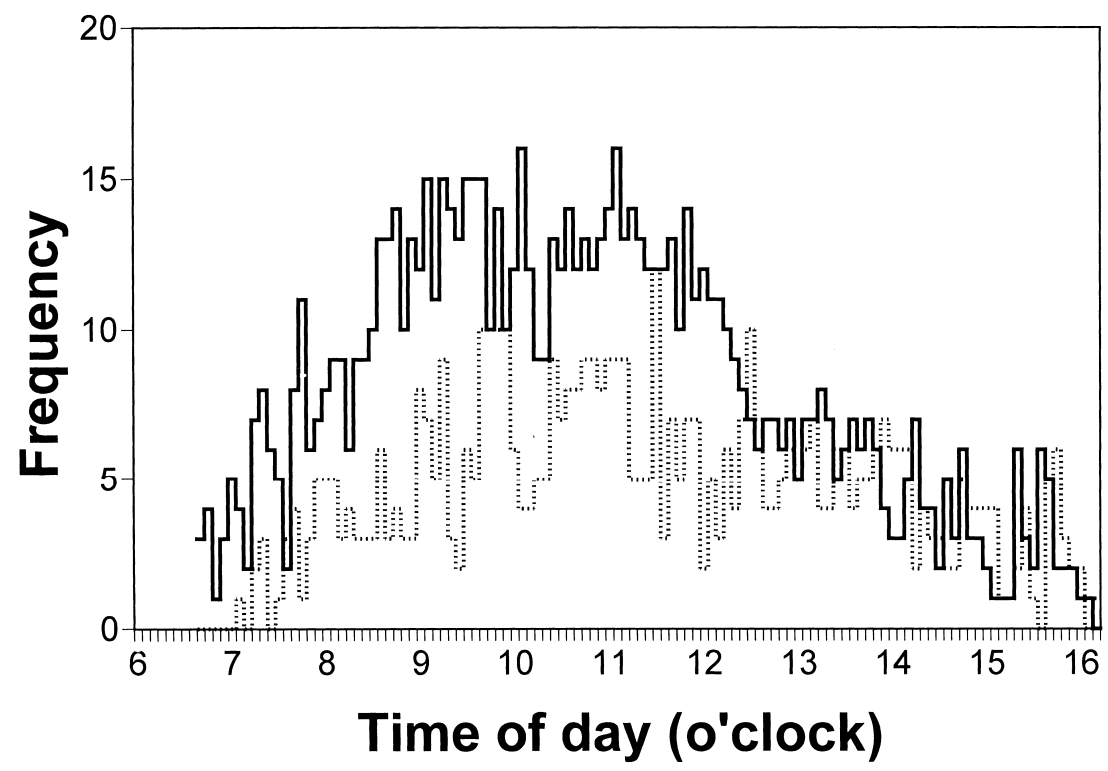

Fig. 1. The number of males searching for females (solid line) and feeding (dotted line) plotted against the day time. The data are from 24 males whose behaviors were followed from dawn to dusk. 


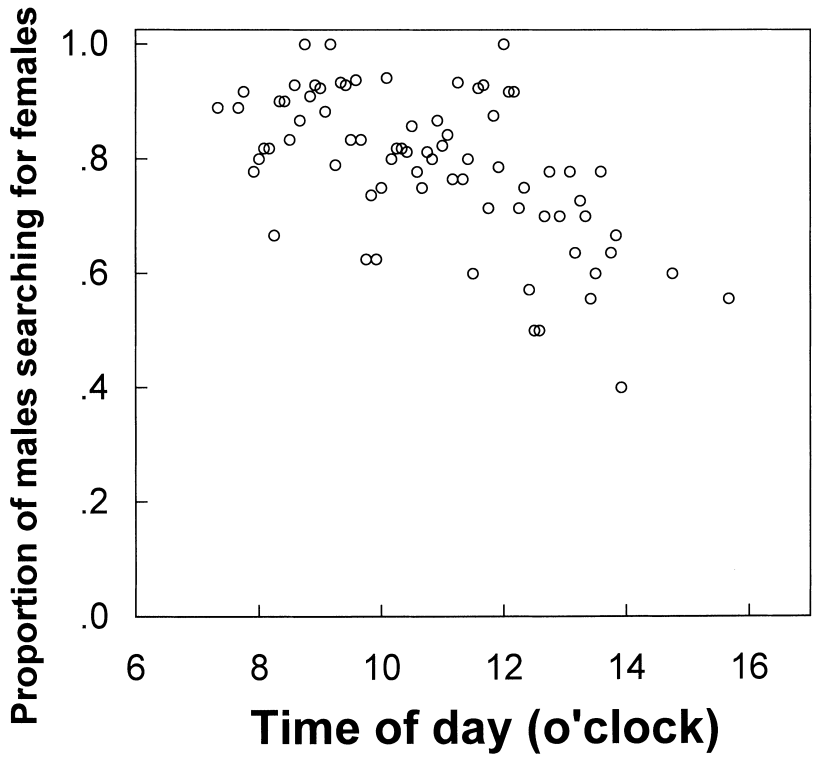

Fig. 2. The proportion of males searching for females out of the active males (female-search + feeding).

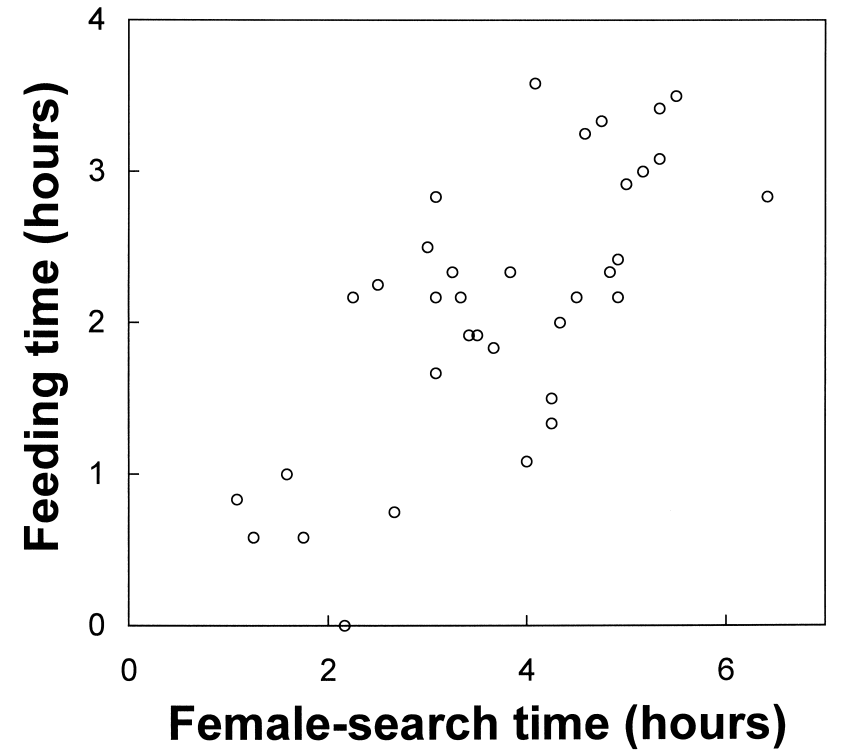

Fig. 3. The correlation between female-searching and feeding time in a day.
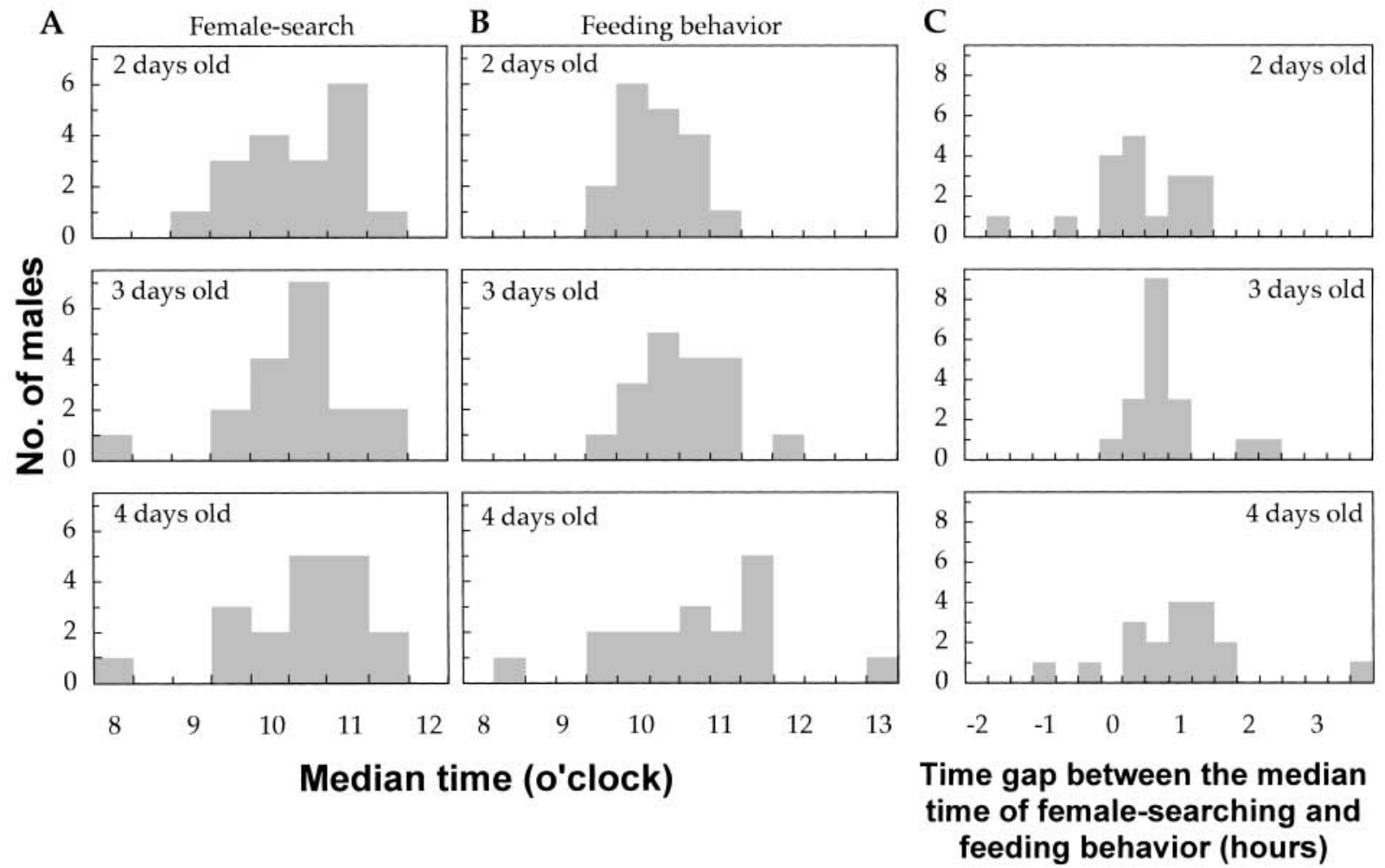

Fig. 4. The effect of adult age on the median time of either female-search or feeding behavior. All figures represent data on the same 18 males. $A$, The female-search did not correlate significantly with the adult age $(T c=0.11, p=0.56)$. B, The feeding behavior correlated positively with the adult age $(T c=0.31, p=0.045)$. $C$, The time gap between female-search and feeding showed a significant positive correlation with adult age $(\mathrm{Tc}=0.37, \mathrm{p}=0.019)$.

behavior to that of female-search was neither significantly correlated with males' adult age $(T c=0.22, k=18, n=3, p=0.18)$.

The body weight of male butterflies decreased as they aged (Fig. 5). On average they lost ten percent or more of the body weight over the first four days after emergence. For 11 males, whose body weight was measured successfully for four consecutive days, there was a significant negative correlation between the adult age and body weight (Fig. 5, Tc=0.82, $\mathrm{k}=11$ males, $n=4$ days, $p<0.001)$. The same is true for eight males whose body weight were successfully measured for longer period $(1,2,3,5$ and 7 days of age, $\mathrm{Tc}=0.54, \mathrm{k}=8, \mathrm{n}=5$, $\mathrm{p}<0.001)$. 


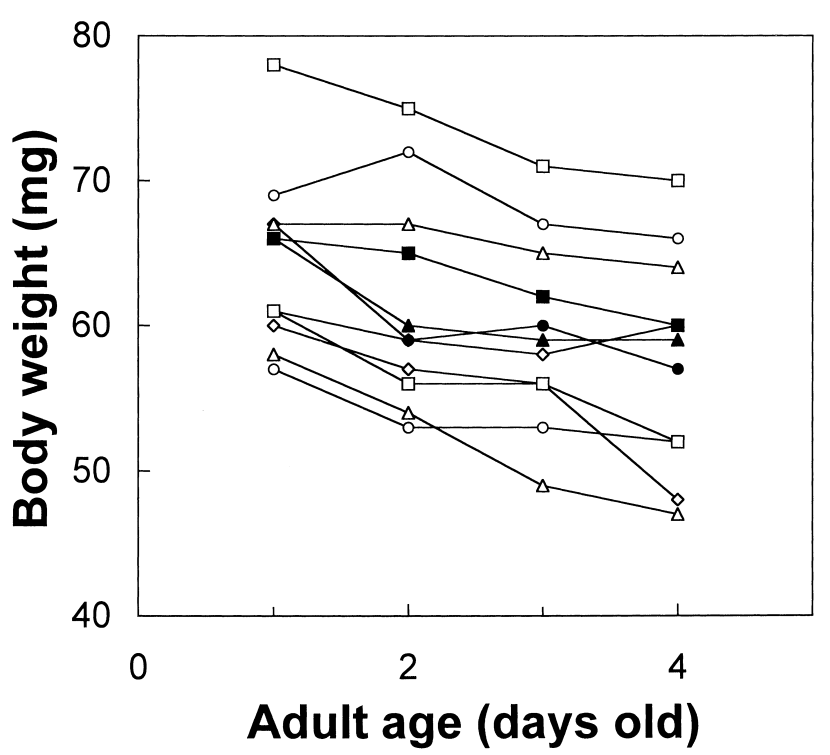

Fig. 5. The change in the body weight of eleven male butterflies during the first four days.

\section{DISCUSSION}

\section{Proximal aspects of female-search}

The present study revealed that male $P$. rapae crucivora alternated time allocation between reproductive and feeding behaviors in a day (Fig. 1). They often shuttled between the cabbage field and nectar flowers respectively to search for females and to feed. This behavioral pattern suggests that males should not devote themselves exclusively to femalesearch even in the late morning which is the time of day when receptive female are expected to be the most available in the day (Iwasa and Obara, 1989). One possible explanation is that physiological constraints require males to sip nectar to supplement energy for female-search flights. $P$. rapae crucivora males fly about energetically close to the ground in a zigzag course to seek out virgin females on the underside of host-plant leaves (Obara, 1964; Ohtani, 1985). In the course of female-search, they frequently encounter many obstacles such as host and other plants, and they have to avoid them to reach the sites where females stay. They are, therefore, frequently required to hover, fly backwards, turn sharply, hoick quickly to fly over the cabbage, fly down close to the ground and maneuver to fly underneath cabbage leaves. It is, therefore, likely that female-search behavior is energetically costly and rapidly exhausts the carbohydrates that are the immediate energy source for the insects. The positive correlation between the time spent in female-search and the time spent in feeding (Fig. 3) may be consistent with the energy constraint alternative. Those males who spent longer searching for females should need to spend more time in feeding to replenish the consumed energy.

The present study also revealed that the males changed the time allocated to reproductive and feeding behaviors as they aged, at least over the four days after emergence (Fig. 4). Older males delayed their feeding behavior and fed more frequently in the afternoon, but did not change the time slot for female-search, which they pursued persistently in the morning. This altered time allocation would improve males' reproductive success, because it results in longer femalesearch behavior in the more profitable time slot. The altered time allocation, however, challenges the energy constraint explanation for the alternated reproductive and feeding behaviors. How and why do aged males alter time allocation to reproductive and feeding behaviors?

One possible factor involved in the altered time allocation may be the reduction in body weight with age (Fig. 5). The present study showed that males lost weight appreciably as they aged. They lost about ten percent of their weight between day 1 and day 4 , and continued to lose weight thereafter. It follows that as a male butterfly becomes older, search flights for females will require less energy and he will be able to search for longer, with less frequent feeding, at the same level of energy cost. On the other hand, it is possible that the age-dependent reduction of energy efficiency might cause the delay of feeding behavior. If older males should spend more time in visiting flowers after search flights, it appeared that time slot of feeding behavior delayed as males aged. However, in the present study the termination time of feeding behaviors was not correlated significantly with male age.

Whether aging improves or worsens energy-efficiency, it results in significant correlation between males' age and their energy efficiency. However, we failed to detect the significant association between male age and the ratio of diurnal feeding duration to diurnal female-searching duration. The further studies were necessary to reveal the proximal causes of agedependent delay of feeding behavior.

\section{Ultimate aspects of female-search}

Aside from the change of energy efficiency in flight, the time allocation to feeding behavior should be subject to a tradeoff between present and future reproduction, if continuing to search for females without taking nutrients sacrifices future reproduction (e.g. Iwasa and Odendaal, 1984). If so, the strategies for reproduction and feeding might change as the butterflies age. The younger males need to visit flowers frequently, even in the morning, to ensure that they survive to search for females on the following days. Regular feeding by young males maybe safeguards future reproduction. In contrast, the older males should give precedence to reproduction over feeding and schedule longer periods of searching for females in the morning, with the feeding behavior delayed until later in the afternoon, since they have less probability of surviving to the next day. However, the present study provided little evidence to discuss on this point, because the oldest male whose behavior was observed was four days old, which is a short time compared with the mean life span of two weeks in $P$. rapae crucivora (Suzuki, 1978; Yamamoto, 1981), although Ohsaki (1980) estimated that the mean life span in field is 6.8 days by mark and recapture methods.

Another explanation for the altered time allocation notes the optimization of the feeding efficiency. If $F$. esculentum 
supplied more nectar in the afternoon than in the morning, male butterflies might learn to schedule feeding in the later, and more profitable time slot. Indeed, it has been noted that flowering plants change the quantity and quality of nectar hourly (Morse and Fritz, 1983), to which such insects as honeybees fit their foraging schedule. However, pollinators were observed to visit the flowers of $F$. esculentum mainly in the later morning (Kaji, personal communication). It implicated that $F$. esculentum supplied more nectar not in the afternoon, but in the later morning. Further studies need to reveal the phenology of nectar production of $F$. esculentum, which was reported scarcely.

Above two ultimate factors are not exclusive alternatives, unlike two proximal factors on energy-efficiency. We would examine the preconditions assumed in four factors, including two proximal ones and two ultimate ones, so that it could be revealed which of those factors worked and contributed to the age-dependent delay of feeding time more than others.

\section{ACKNOWLEDGMENT}

We thank greatly Dr. Michael E. N. Majerus, Dr. Tamsin M. Majerus and anonymous referees for critically reading the manuscript and improving English. We thank Kikue Hamano for the assistance in observation and breeding insects. This works was supported in part by a Grant-in-Aid for Scientific Research from the Ministry of Education, Sports and Culture of Japan (09041151).

\section{REFERENCES}

Emlen ST, Oring LW (1978) Ecology, sexual selection, and the evolution of mating systems. Science 197: 215-223

Fretwell SD (1972) Popuation in a Seasonal Environment, Princeton University Press, New Jersey

Iwasa Y, Obara Y (1989) A Game Model for the Daily Activity Schedule of the Male Butterfly. Journal of Insect Behavior 2: 589-608

Iwasa Y, Odendaal FJ (1984) A theory on the temporal pattern of operational sex ratio during the breeding season; The activeinactive model. Ecology 65: 886-893

Kvarnemo C, Ahnesjö I (1996) The dynamics of operational sex ratios and competition for mates. Trends in Ecology \& Evolution 11: $404-408$
Morse DH, Fritz RS (1983) Contributions of diurnal and nocturnal insects to the pollination of common milkweed (Asclepias syriaca L.) in a pollen-limited system. Oecologia 60: 190-197

Obara Y (1964) Mating behavior of the cabbage butterfly, Pieris rapae crucivora. II. The "mate refusal posture" of the female. Dobutsugaku Zasshi 73: 175-178

Odendaal FJ, Iwasa Y, Ehrlich PR (1985) Duration of female availability and its effect on butterfly mating systems. American Naturalist 125: 673-678

Ohsaki N (1980) Comparative population studies of three Pieris butterflies, $P$. rapae, $P$. melete, and $P$. napi, living in the same area. II. Utilization of patchy habaitats by adults through migratory and non-migratory movements. Research on Population Ecology 22: $163-183$

Ohsaki N (1982) Comparative population studies of three Pieris butterflies, P. rapae, P. melete, and $P$. napi, living in the same area. III. Difference in the annual generation numbers in the relation to habitat selection by adult. Research on Population Ecology 24: $193-210$

Ohtani T (1985) The adult behavir of the japanese cabbage white (Lepidoptera, Pieridae) in the field I. behavior repertorie observed. Tyo to $\mathrm{Ga} 35$ : $161-173$

Owens IP, Thompson DB (1994) Sex differences, sex ratios and sex roles. Proc R Soc Lond B Biol Sci 258: 93-99

Rutowski RL (1979) The butterfly as an honest salesman. Animal Behavior 27: 1269-1270

Rutowski RL (1991) The evolution of male mate-locating behavior in butterflies. American Naturalist 138: 1121-1139

Siegel S, Castellan NJJ (1988) Nonparametric Statistics for the Behavioral Sciences. Second, McGraw Hill,

Suzuki Y (1978) Adult longevity and reproductive potential of the small cabbage white, Pieris rapae crucivora Boisduval (Lepidoptera: Pieridae). Applied Entomology and Zoology 13: 311-312

Suzuki $Y$ (1980) The forming process of male-biased sex ration at an emergence site in Pieris rapae crucivora Bosiduval (Lepidoptera, Pieridae). Kontyû 48: 299-306

Thornhill R, Alcock J (1983) The evolution of insect mating systems, United States of America

Yamamoto M (1981) Adult duration of the Japanese cabbage white, Pieris rapae cruivora (Lepidoptera: Pieridae). Applied Entomology and Zoology 16: 310-312

(Received April 17, 1999 / Accepted October 26, 1999) 